University of Wollongong

Research Online

Australian Institute for Innovative Materials -

Papers

Australian Institute for Innovative Materials

2016

\title{
3-D structured SnO2-polypyrrole nanotubes applied in Na-ion batteries
}

Boyang Ruan

University of Wollongong, br970@uowmail.edu.au

Haipeng Guo

University of Wollongong, hg476@uowmail.edu.au

Qiannan Liu

University of Wollongong, q1953@uowmail.edu.au

Dongqi Shi

University of Wollongong, dongqi@uow.edu.au

Shulei Chou

University of Wollongong, shulei@uow.edu.au

See next page for additional authors

Follow this and additional works at: https://ro.uow.edu.au/aiimpapers

Part of the Engineering Commons, and the Physical Sciences and Mathematics Commons

Research Online is the open access institutional repository for the University of Wollongong. For further information contact the UOW Library: research-pubs@uow.edu.au 


\title{
3-D structured SnO2-polypyrrole nanotubes applied in Na-ion batteries
}

\author{
Abstract \\ SnO2-coated polypyrrole (PPy) with a three-dimensional (3-D) structured nanotube network has been \\ prepared via a facile hydrothermal method and tested as an anode material for $\mathrm{Na}$-ion batteries. The \\ crystalline $\mathrm{SnO} 2$ nanoparticles (less than $25 \mathrm{~nm}$ in size) are distributed uniformly on the surfaces of the \\ PPy tubes. When it is used as an anode material for sodium-ion batteries (SIBs), the composite electrode \\ can deliver a good reversible capacity of nearly $288 \mathrm{~mA} \mathrm{~h} \mathrm{g-1} \mathrm{when} \mathrm{discharging} \mathrm{at} 100 \mathrm{~mA} \mathrm{~g}-1$, with more \\ than $69.1 \%$ capacity retention and stable coulombic efficiency of $99.6 \%$ after 150 cycles. The good \\ electrochemical performance compared to the $151 \mathrm{~mA} \mathrm{~h} \mathrm{g-1}$ achieved by bare SnO2, which was \\ fabricated by the same method in the absence of PPy, could be mainly attributed to the good dispersion \\ of SnO2 on the 3-D matrix of PPy tubes, which facilitates the diffusion of $\mathrm{Na}+$ ions and buffers the large \\ volumetric changes during charge/discharge. Our results suggest that such $\mathrm{SnO} 2 /$ carbonaceous \\ composites would be good anode candidates for SIBs. \\ Disciplines \\ Engineering | Physical Sciences and Mathematics

\section{Publication Details} \\ Ruan, B., Guo, H., Liu, Q., Shi, D., Chou, S., Liu, H., Chen, G. \& Wang, J. (2016). 3-D structured \\ SnO2-polypyrrole nanotubes applied in Na-ion batteries. RSC Advances: an international journal to further \\ the chemical sciences, 6 (105), 103124-103131.

\section{Authors} \\ Boyang Ruan, Haipeng Guo, Qiannan Liu, Dongqi Shi, Shulei Chou, Hua-Kun Liu, Guohua Chen, and Jiazhao \\ Wang
}




\section{Journal Name}

\section{ARTICLE}

\section{3-D structured $\mathrm{SnO}_{2}$-Polypyrrole Nanotubes}

Received 00th January 20xx, Accepted 00th January 20xx

DOI: $10.1039 / x 0 x \times 00000 x$

\section{Applied in Na-ion Batteries}

www.rsc.org/

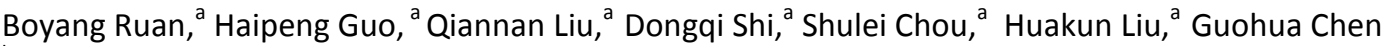 \\ b and Jiazhao Wang* ${ }^{\text {a }}$
}

\section{Introduction}

Lithium-ion batteries (LIBs) have been receiving tremendous attention as promising energy-storage and transformation devices, and they are widely applied in portable electronic devices, electric vehicles, hybrid electrical vehicles, etc. Now, they are becoming indispensable energy storage devices for application in the energy conversion of intermittent energy sources, such as in solar cell arrays and wind power stations. Considering these factors along with the limited reserves and non-uniform distribution of lithium resources, the big challenges for long-run and large-scale applications of lithiumion batteries related their availability and cost are becoming more and more prominent. Based on the above issues, it is an urgent necessity to develop new types of batteries. Over the past several years, sodium-ion batteries (SIBs), which are becoming known as future alternatives to lithium ion batteries, have been attracting great attention, ${ }^{1,2}$ mainly in view of the abundance of sodium resources and their obvious cost-

\footnotetext{
a. Institute for Superconducting and Electronic Materials(ISEM), AIIM Facility, Innovation Campus, University of Wollongong, Squires Way, North Wollongong, NSW 2500, Australia.

E-mail: jiazhao@uow.edu.au (JZW)

Tel: +61 24298 1478; Fax: +61 242215731

b. Department of Chemical and Biomolecular Engineering, The Hong Kong University of Science and Technology, Clearwater Bay, Hong Kong, China
}

effective advantages. ${ }^{3-9}$ As is well known, it is still a big challenge to develop suitable anode materials for $\mathrm{Na}$-ion batteries because of the larger ionic radius of $\mathrm{Na}^{+}$compared to that of $\mathrm{Li}^{+}$, which causes greater volume changes during cycling and lower gravimetric and volumetric energy densities. These innate characteristics are directly limiting the feasibility of insertion materials for SIBs, including some cathode and anode materials. To bypass these deficiencies, many carbon-based materials have been extensively investigated, such as hard carbons, which can achieve reversible capacities from 200 to $290 \mathrm{mAh} \mathrm{g}^{-1}$ for more than 180 and 100 cycles, respectively. ${ }^{10,}$ ${ }^{11}$ Reduced graphene oxide, could achieve a reversible capacity of $174.3 \mathrm{mAh} \mathrm{g}^{-1}$ over 250 cycles. ${ }^{12} \mathrm{~N}$-doped carbon composite, which showed a reversible capacity of $155.2 \mathrm{mAh} \mathrm{g}^{-1}$ after 260 cycles, ${ }^{13}$ retained a reversible capacity of $243 \mathrm{mAh} \mathrm{g}^{-1}$ after 100 cycles, ${ }^{14}$ and achieved a specific capacity of $175 \mathrm{mAh} \mathrm{g}^{-1}$ after 2000 cycles etc. ${ }^{15}$ Some non-carbonaceous materials such as metal oxide materials also have been studied for SIBs. ${ }^{16-20}$ Among these materials, $\mathrm{SnO}_{2}$-based materials have attracted more interest because $\mathrm{SnO}_{2}$ can deliver high specific capacities by acting as an alloying material to store $\mathrm{Na}$. It has been demonstrated that $\mathrm{SnO}_{2}$ can be an attractive anode for SIBs, with a capacity of $667 \mathrm{~mA} \mathrm{~h} \mathrm{~g} \mathrm{~g}^{-1}$, based on the following reactions: $4 \mathrm{SnO}_{2}+16 \mathrm{Na}^{+}+16 \mathrm{e}^{-} \longrightarrow 4 \mathrm{Sn}+8 \mathrm{Na}_{2} \mathrm{O}$ $4 \mathrm{Sn}+15 \mathrm{Na}^{+}+16 \mathrm{e}^{-} \longleftrightarrow \mathrm{Na}_{15} \mathrm{Sn}_{4}{ }^{[20]}$ (2). Similarly, the main disadvantages of $\mathrm{SnO}_{2}$ are the expansion and shrinkage of the active material particles during $\mathrm{Na}$ insertion/extraction, leading to particle pulverization/ exfoliation and rapidly 
decreasing capacity in these materials. ${ }^{5,20}$ On the other hand, studies have shown that the diffusion speed of $\mathrm{Na}^{+}$is 30 times slower than that of $\mathrm{Li}^{+}$in $\mathrm{SnO}_{2}$ particles. ${ }^{21}$ Much research has been carried out to solve this problem, such as by decreasing the particle size of the active material to the nanoscale ${ }^{22}$ and loading some materials as buffer layers. ${ }^{20,23-29}$ In recent years, with the persistent efforts focused on exploring new anode materials for sodium storage, some three-dimensional (3-D) structured composites have been recognised to have sodium storage capability. There are many reports of $\mathrm{SnO}_{2}$ nanoparticles loaded onto graphene, ${ }^{25}$ anchored on reduced graphene oxide frameworks ${ }^{30}$ and confined in mesoporous carbon. $^{31}$

Polypyrrole (PPy), in particular consisting of tubes with a 3-D structure, as a kind of conducting polymer, not only acts as an electrically conducting agent, which is beneficial for reducing resistance and enhancing the rate capability of the cell, but also as a matrix or binder, which can provide efficient transport pathways for electrons and mitigate the pulverization of the electrode brought about by the huge volume expansion during the charging/discharging process. This unique hierarchical structure not only provides good structural robustness and short ion/electron diffusion pathways, but also promotes the diffusion of the electrolyte into the inner spaces of the material, as well as providing sufficient open channels for fast $\mathrm{Na}^{+}$migration. There are many reports on using PPy as a matrix to synthesize $\mathrm{SnO}_{2}$ based composites $^{32-36}$ for anode materials. Recently, Du and Wang reported the synthesis of $\mathrm{SnO}_{2} @$ polypyrrole nanotubes with microwave-assisted method. ${ }^{37}$ The pyrolyzed composite displayed very excellent capability for Li-storage as the PPy NTs can accommodate large volume change of the electrode material during $\mathrm{Li}^{+}$insertion/extraction, which prevented $\mathrm{SnO}_{2}$ nanoparticles from pulverizing and electrical isolating during cycling. Combining PPy tubes with $\mathrm{SnO}_{2}$ nanoparticles to fabricate $\mathrm{SnO}_{2}$-based anode material in $\mathrm{SIBs}$ has not been explored, however. In term of the above advantages, we also adopted PPy as the substrate material and anchored the active $\mathrm{SnO}_{2}$ nanoparticles on its' surface.

Herein, we report the in situ hydrothermal synthesis of $\mathrm{SnO}_{2}$ PPy nanotubes with a 3-D structure. In the composites, $\mathrm{SnO}_{2}$ nanoparticles are homogeneously distributed on the surfaces of the PPy nanotubes. This unique hierarchical structure not only provides good structural robustness and short ion/electron diffusion pathways, but also has benefits for electrolyte penetration and $\mathrm{Na}^{+}$transport. The obtained 3-D structured $\mathrm{SnO}_{2}$-PPy nanotube network showed a good reversible capacity of nearly $288 \mathrm{~mA} \mathrm{~h} \mathrm{~g}^{-1}$ when discharging at $100 \mathrm{~mA} \mathrm{~g}^{-1}$, with more than $69.1 \%$ capacity retention and stable Coulombic efficiency of $99.6 \%$ over 150 cycles. Good rate capability is observed, based on current rate variation during cycling from $50 \mathrm{~mA} \mathrm{~g}^{-1}$ to $1 \mathrm{Ag}^{-1}$.

\section{Experimental Section}

\section{Synthesis of PPy tubes}

The PPy tubes were synthesized according to a previous report ${ }^{38}$ with some modifications. The process of synthesis was as follows: $1.95 \mathrm{~g}$ of $\mathrm{FeCl}_{3}$ was added to $150 \mathrm{~mL}$ a solution containing $98 \mathrm{mg}$ methyl orange (MO) in deionized water under constant stirring. A flocculent precipitate appeared immediately. Then, $0.484 \mathrm{~g}(0.5 \mathrm{ml})$ of pyrrole monomer was added into the mixture and the mixture was continuously stirred for 24 hours at room temperature. After that, the thusformed PPy precipitate was washed several times with deionized water/ ethanol, until the filtrate was colourless and neutral. Finally, the precipitate was dried under vacuum at 60 ${ }^{\circ} \mathrm{C}$ for $24 \mathrm{~h}$.

\section{Preparation of the $\mathrm{SnO}_{2} @ P P y$ nanocomposites}

In a typical procedure, $0.035 \mathrm{~g}$ hexamethylenetetramine (HMTA) and $0.02 \mathrm{~g}$ urea were dissolved in $30 \mathrm{ml}$ ethanol, and then $0.1 \mathrm{~g}$ PPy was dispersed into the foregoing solution by ultrasonic treatment for $0.5 \mathrm{~h}$. $0.1 \mathrm{~g}$ of $\mathrm{SnCl}_{2} \cdot 2 \mathrm{H}_{2} \mathrm{O}$ was added to the preceding mixture and stirred in for 30 minutes. Subsequently, the resulting blend was transferred into a Teflon-lined autoclave and heated up to $120^{\circ} \mathrm{C}$ for $10 \mathrm{~h}$. When the precipitates were cooled down to room temperature naturally, then washed it with distilled water and ethanol for several times. Drying the precipitates in a vacuum oven overnight at $60{ }^{\circ} \mathrm{C}$, the final product (denoted as $\mathrm{SnO}_{2}-\mathrm{PPy}-1$ ) was obtained. $\mathrm{SnO}_{2}-\mathrm{PPy}-2$ was obtained by adjusting the weight of $\mathrm{SnCl}_{2} .2 \mathrm{H}_{2} \mathrm{O}$ to $0.15 \mathrm{~g}$. For comparison, pure $\mathrm{SnO}_{2}$ nanoparticles were prepared with the same conditions without the addition of PPy.

\section{Materials Characterization}

The powder X-ray diffraction (XRD; GBC MMA diffractometer) equipped with $\mathrm{Cu} K \alpha$ radiation at a scan rate of $2^{\circ} \mathrm{min}^{-1}$ was used to identify the structures of the as-prepared $\mathrm{SnO}_{2}-\mathrm{PPy}$ composites and the precursors. The weight ratio between $\mathrm{SnO}_{2}$ and PPy was determined by thermogravimetric analysis (TGA) using a Mettler Toledo TGA/DSC1 between $40{ }^{\circ} \mathrm{C}$ and $800{ }^{\circ} \mathrm{C}$ at a heating rate of $5{ }^{\circ} \mathrm{C} \mathrm{min}-1$ in air. The valence state of $\mathrm{Sn}$ was evaluated by X-ray photoelectron spectroscopy (XPS) using a SPECS PHOIBOS 100 Analyzer equipped with a highvacuum chamber with base pressure below $10^{-8} \mathrm{mbar}$, with the $\mathrm{X}$-ray excitation generated by $\mathrm{Al} \mathrm{K} \alpha$ radiation at the high voltage of $12 \mathrm{kV}$ and power of $120 \mathrm{~W}$. The data were analyzed with the Casa XPS 2.3.15 software package. All the spectra were calibrated by $\mathrm{C}_{1 \mathrm{~s}}=284.6 \mathrm{eV}$. Field emission scanning electron microscopy (FESEM; JEOL JSM-7500FA) and high resolution transmission electron microscopy (HRTEM; JEOL JSM-2010) were used to investigate the morphology of the samples.

\section{Electrochemical Measurements}


The electrochemical performance testing was carried out via 2032-type coin cells. The working electrode was prepared by preparing a slurry in the mass ratio of $80 \mathrm{wt} \%$ active material, 10 wt \% Super-P (carbon black) and 10 wt \% carboxymethyl cellulose (CMC) binder, and coating it on copper foil substrate. Then the electrode film was dried in a vacuum oven at $80{ }^{\circ} \mathrm{C}$ overnight. An electrolyte with $1.0 \mathrm{~mol} \mathrm{~L}^{-1} \mathrm{NaClO} 4$ in an ethylene carbonate (EC) - diethyl carbonate (DEC) solution $(1: 1 \mathrm{v} / \mathrm{v})$, with $5 \mathrm{wt} \%$ addition of fluoroethylene carbonate (FEC), was used in this work. All the cells were assembled in a glove box filled with argon gas and measured at room temperature. Galvanostatic charge-discharge testing was carried out on a Land Test System with a cut-off voltage range from 0.01 to $1.5 \mathrm{~V}$ (vs. $\mathrm{Na} / \mathrm{Na}^{+}$) at different current densities. The capacities are calculated based on the weight of the composites. Cyclic voltammetry and electrochemical impedance measurements were conducted using a Biologic VMP-3 electrochemical workstation from $0.005 \mathrm{~V}$ to $2.5 \mathrm{~V}$ (vs. $\mathrm{Na} / \mathrm{Na}^{+}$) at a scan rate of $0.1 \mathrm{mV} \mathrm{s}^{-1}$.

\section{Results and Discussion}

The XRD patterns of the PPy, $\mathrm{SnO}_{2}$ particles, and the $\mathrm{SnO}_{2}-\mathrm{PPy}-$ 1 and $\mathrm{SnO}_{2}-\mathrm{PPy}-2$ composites are displayed in Fig. 1a. The PPy spectrum reveals a clear broad peak at about $23.8^{\circ}$ corresponding to its' amorphous nature, which is due to the scattering from PPy chains at the interplanar spacing. ${ }^{39-41}$ The XRD pattern of the $\mathrm{SnO}_{2}$ nanoparticles was characterized by several peaks which could be ascribed to the tetragonal $\mathrm{SnO}_{2}$ structure (cassiterite, PDF no. 01-0625) without any impurity. These large peaks clearly demonstrated the formation of small $\mathrm{SnO}_{2}$ particles with a nanocrystalline nature. From the XRD patterns of the obtained $\mathrm{SnO}_{2}-\mathrm{PPy}-1$ and $\mathrm{SnO}_{2}-\mathrm{PPy}-2$ composites, we find very similar broad peaks that could also be indexed to the tetragonal $\mathrm{SnO}_{2}$ structure (cassiterite, PDF no. 01-0625). No other characteristic peaks can be seen, suggesting that the $\mathrm{SnO}_{2}$ nanoparticles have covered the surfaces of the PPy.

For quantifying the amount of PPy in the $\mathrm{SnO}_{2}$-PPy composites, thermogravimetric analysis (TGA) measurements were carried out in air. The TGA curves of pure PPy and its composites are shown in Fig. 1b. It can also be seen that both pure PPy and its composites show weight loss in the temperature range of 250$650{ }^{\circ} \mathrm{C}$, which is in accordance with the oxidation of PPy, although the temperatures at which weight loss ends in the three samples have some differences. For pure PPy and $\mathrm{SnO}_{2}-$ $\mathrm{PPy}-1$, there was no difference. $\mathrm{SnO}_{2}-\mathrm{PPy}-2$ required a higher temperature to oxidize PPy compared to pure PPy. This phenomenon could be the result of the greater amount of $\mathrm{SnO}_{2}$ loaded onto the PPy, which delayed the PPy oxidation process. After the initial oxidation of PPy, no further weight change was observed in the composites. Therefore, the weight change due to the oxidation of PPy can be directly converted into the amount of PPy in the $\mathrm{SnO}_{2}$-PPy composites. Using this approach, we calculated that the amounts of PPy in the $\mathrm{SnO}_{2}$ $\mathrm{PPy}-1$ and $\mathrm{SnO}_{2}-\mathrm{PPy}-2$ composites were $61.4 \mathrm{wt} \%$ and, 38.4 $w t \%$, respectively.
The Fourier transform infrared (FTIR) spectra of bare $\mathrm{SnO}_{2}$, $\mathrm{PPy}, \mathrm{SnO}_{2}-\mathrm{PPy}-1$, and $\mathrm{SnO}_{2}-\mathrm{PPy}-2$ are shown in Fig. 1c. In the spectrum for $\mathrm{SnO}_{2}$, a strong vibration around $609 \mathrm{~cm}^{-1}$ is observed in the low wave number range, which is indexed to the antisymmetric $\mathrm{Sn}-\mathrm{O}-\mathrm{Sn}$ mode of tin oxide. In the spectrum for PPy, the band centered at $1560 \mathrm{~cm}^{-1}$ corresponds to typical $\mathrm{C}=\mathrm{C}$ in plane vibration, while the characteristic bands at 1300 and $1205 \mathrm{~cm}^{-1}$ are connected with $\mathrm{C}-\mathrm{C}$ and $\mathrm{C}-\mathrm{H}$ ring stretching, respectively. The sharp peak at $1052 \mathrm{~cm}^{-1}$ is ascribed to $\mathrm{C}-\mathrm{H}$ in-plane vibrations. The band at $929 \mathrm{~cm}^{-1}$ can be attributed to $\mathrm{N}-\mathrm{H}$ in-plane vibrations. ${ }^{42}$ In the spectra of
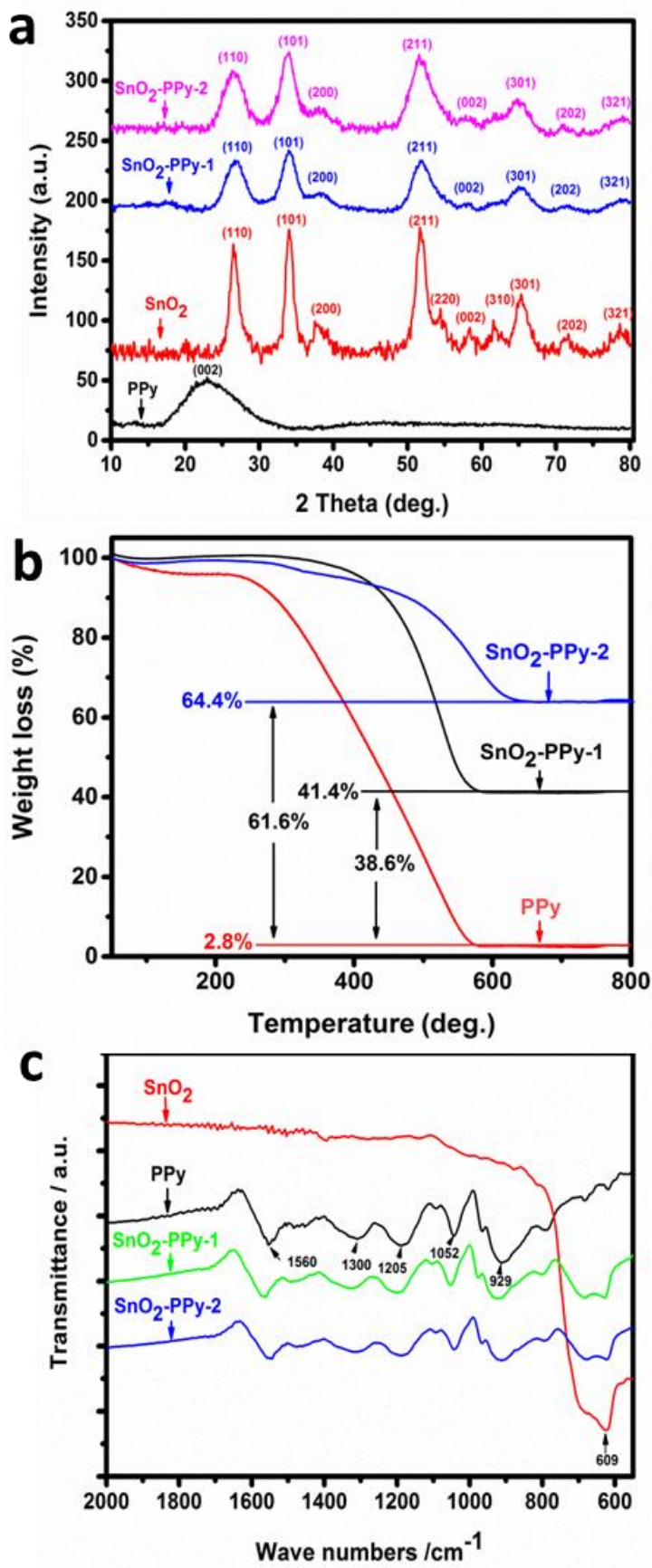

Figure 1 XRD patterns (a), TGA curves (b) and FTIR spectra (c) of PPy, bare $\mathrm{SnO}_{2}$ and $\mathrm{SnO}_{2}$-PPy composite. 


\section{a}

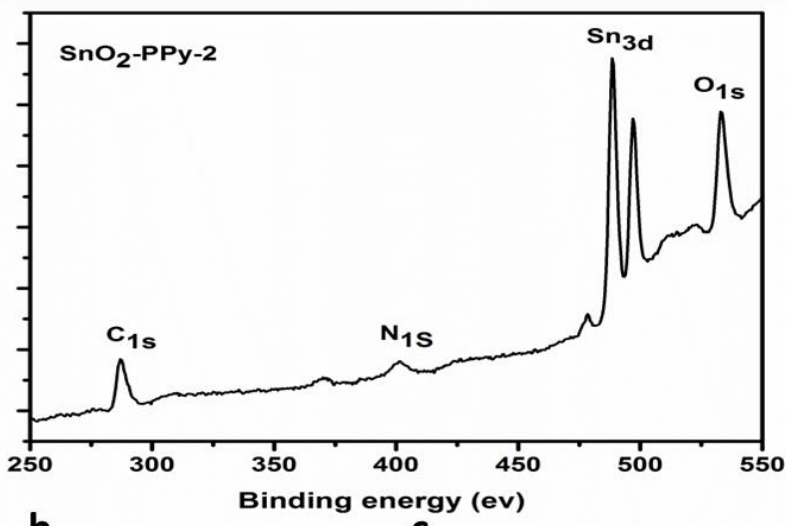

b

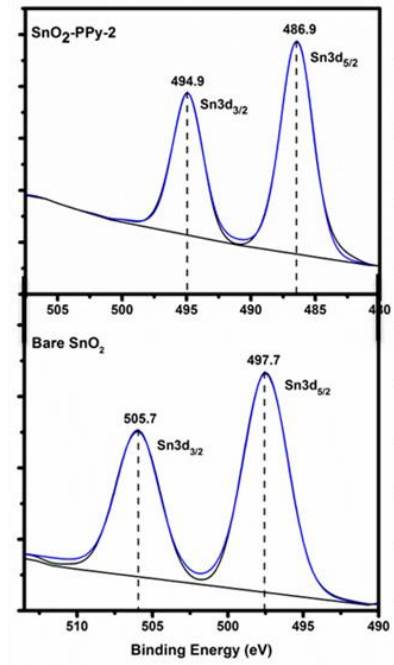

C

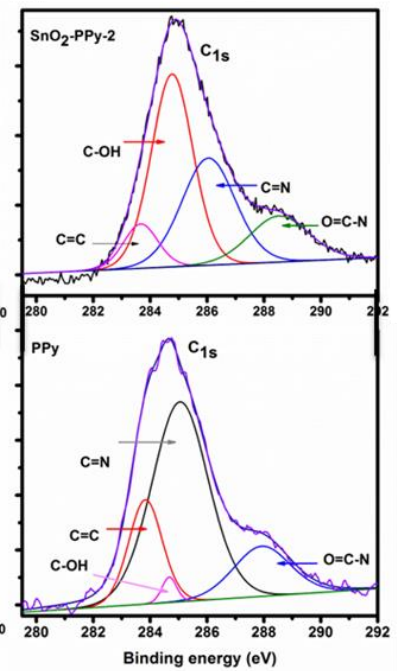

Figure 2 XPS spectra: survey spectrum (a) for $\mathrm{SnO}_{2}-\mathrm{PPy}-2$ ( PPy $38.4 \%$ ) composite, and high resolution spectra of $\mathrm{Sn}_{3 d}$ (b) for bare $\mathrm{SnO}_{2}$ and $\mathrm{SnO}_{2}-\mathrm{PPy}-2$ composite, and $\mathrm{C}_{1 \mathrm{~s}}$ (c) for PPy and $\mathrm{SnO}_{2}$-PPy-2 (PPy $38.4 \%$ ) composite.

$\mathrm{SnO}_{2}-\mathrm{PPy}-1$ and $\mathrm{SnO}_{2}-\mathrm{PPy}-2$, all the characteristic bonds for both $\mathrm{SnO}_{2}$ and PPy can be clearly observed. Therefore, the FTIR results confirm the presence of both $\mathrm{PPy}$ and $\mathrm{SnO}_{2}$ in the $\mathrm{SnO}_{2}$-PPy nanocomposites.

To investigate the interaction between the $\mathrm{PPy}, \mathrm{SnO}_{2}$ and $\mathrm{SnO}_{2}-\mathrm{PPy}-2, \mathrm{X}$-ray photoelectron spectroscopy (XPS) was used to detect the chemical states of elements. Peaks for $\mathrm{C}, \mathrm{Sn}$, and $\mathrm{O}$ in $\mathrm{SnO}_{2}-\mathrm{PPy}-2$ were founded in the XPS survey spectrum, as shown in Fig. 2a. The $\mathrm{Sn}_{3 d}$ XPS spectra of $\mathrm{SnO}_{2}$ and $\mathrm{SnO}_{2}-\mathrm{PPy}-2$ were collected to investigate the changes in the chemical state of tin before and after the hydrothermal reaction. In Fig. 2b, for both materials, there are two peaks, and the binding energy interval between them is $8 \mathrm{eV}$, which is consistent with the energy splitting of $\mathrm{Sn}$ or $\mathrm{SnO}_{2}{ }^{43}$ For bare $\mathrm{SnO}_{2}$, the peaks found at $497.7 \mathrm{eV}$ and $505.7 \mathrm{eV}$ correspond to the $3 \mathrm{~d}_{5 / 2}$ and $3 \mathrm{~d}_{3 / 2}$ curves of $\mathrm{Sn}$ (IV) in $\mathrm{SnO}_{\mathrm{x}} \cdot{ }^{44,45}$ When $\mathrm{SnO}_{2}$ is coated with PPy, $\mathrm{Sn}_{3 \mathrm{~d}}$ peaks are shifted towards lower binding energies, i.e., $486.9 \mathrm{eV}$ and $494.9 \mathrm{eV}$. These differences in the peak locations are obviously induced by the presence of PPy, which is conductive, while the bare $\mathrm{SnO}_{2}$ nanoparticles behave as an insulator in term of the XPS results. ${ }^{31}$ In the $C_{1 s}$ spectra for bare
$\mathrm{SnO}_{2}$ and $\mathrm{SnO}_{2}-\mathrm{PPy}-2$, there is no obvious peak change, which means the absence of C-Sn bonds. This result indicates that no chemical reaction occurred during the preparation and that the composit structure is held together by van der Waals forces.

The morphologies of PPy, bare $\mathrm{SnO}_{2}, \mathrm{SnO}_{2}-\mathrm{PPy}-1$ and $\mathrm{SnO}_{2}-$ PPy-2 were characterized by scanning electron microscopy (SEM), as shown in Fig. 3. The image of PPy shows a homogeneous morphology of strip-like 3-D structured tubes about 300-450 nm in diameter (Fig.3a and 3e). For $\mathrm{SnO}_{2}-\mathrm{PPy}-1$ and $\mathrm{SnO}_{2}-\mathrm{PPy}-2$, in Fig. $3 \mathrm{~b}, 3 \mathrm{c}, 3 \mathrm{f}, 3 \mathrm{~g}$, the coarse surface can be clearly observed, with the diameters of the tubes apparently increased compared to PPy. There is not obvious difference in the shape of $\mathrm{SnO}_{2}-\mathrm{PPy}-1$ and $\mathrm{SnO}_{2}-\mathrm{PPy}-2$. Fig. 3d and 3h show the bare $\mathrm{SnO}_{2}$ nanoparticles at different magnifications. The size of the $\mathrm{SnO}_{2}$ particles is similar to that in the composites.

The uniformity of the material composition was also confirmed

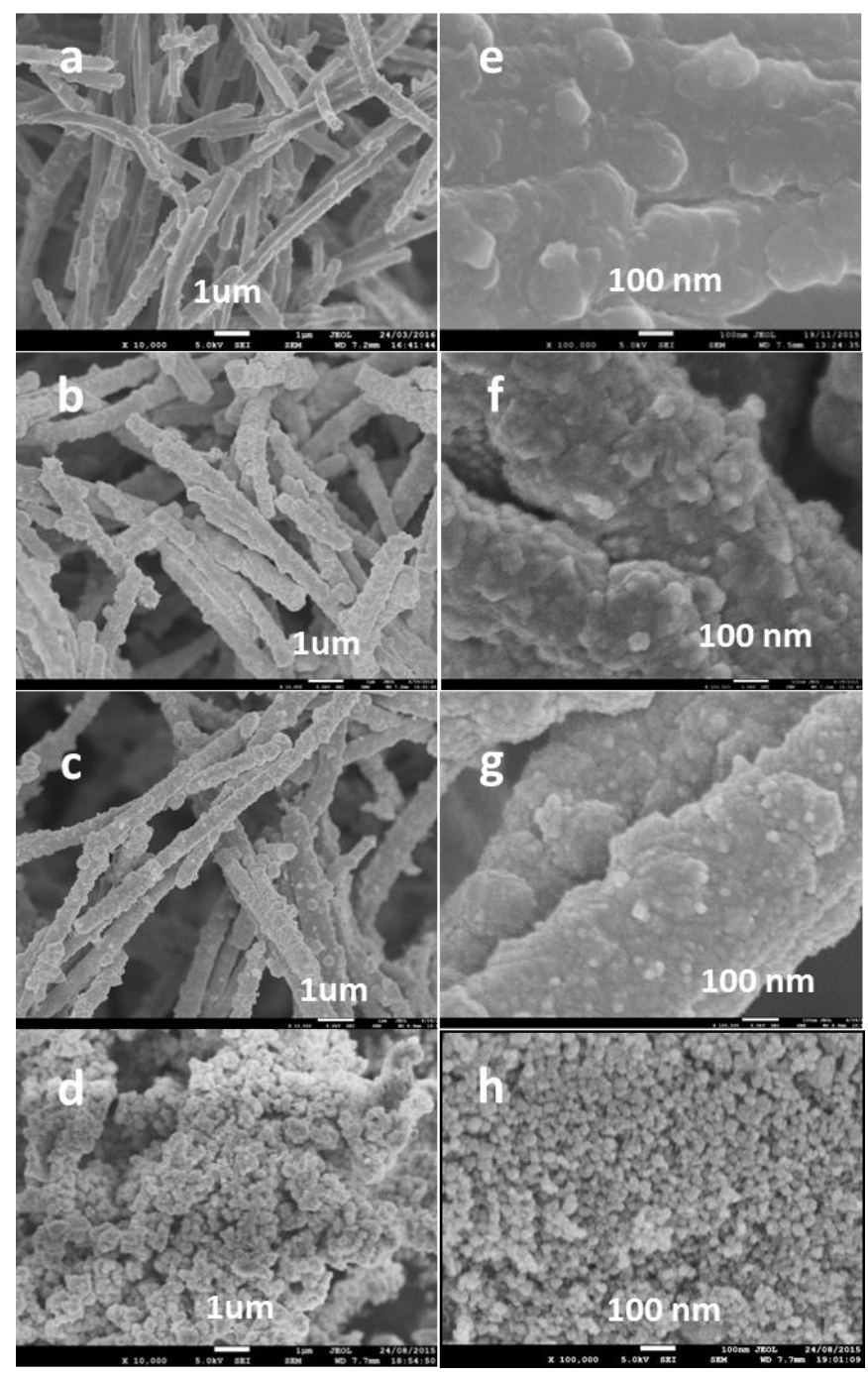

Figure $3 \mathrm{SEM}$ images at low magnification of PPy (a), $\mathrm{SnO}_{2}-\mathrm{PPy}$ 1 (PPy 61.4\%) (b), $\mathrm{SnO}_{2}-\mathrm{PPy}-2$ (PPy 38.4\%) (c), and bare $\mathrm{SnO}_{2}$ (d); and SEM images at high magnification of PPy (e), $\mathrm{SnO}_{2}-$ PPy-1 (PPy 61.4\%) (f), $\mathrm{SnO}_{2}-\mathrm{PPy}-2$ (PPy 38.4\%) (g), and bare $\mathrm{SnO}_{2}(\mathrm{~h})$. 

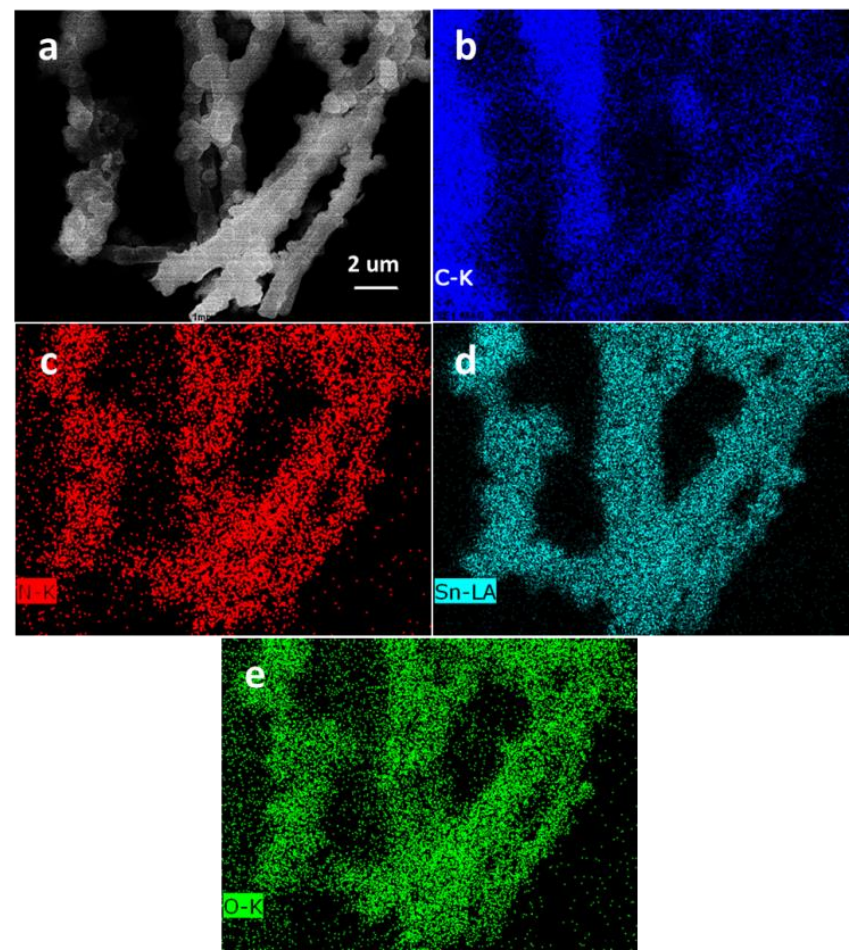

Figure 4 Dark field image of $\mathrm{SnO}_{2}-\mathrm{PPy}-2$ (PPy 38.4\%) (a), with corresponding EDS elemental mappings of $C(b), N(c), S n(d)$, and $\mathrm{O}(\mathrm{e})$.

by energy dispersive X-ray spectroscopy (EDS) mapping, as illustrated in Fig.4. For the elemental mapping of $\mathrm{Sn}$ and $\mathrm{O}$, the points clearly indicate that the $\mathrm{SnO}_{2}$ was homogeneously distributed on the PPy tubes.

Transmission electron microscopy (TEM) was further used to investigate the changes in structure between $\mathrm{PPy}$ and $\mathrm{SnO}_{2}-$ $\mathrm{PPy}-1, \mathrm{SnO}_{2}-\mathrm{PPy}-2$ composites. As displayed in Fig. $5 \mathrm{a}$ and $5 \mathrm{~b}$, $5 \mathrm{c}$ before coating with $\mathrm{SnO}_{2}$, the diameter of PPy is less than $450 \mathrm{~nm}$. The diameters of the tubes were significantly increased for the both composites, and the diameters are larger than $550 \mathrm{~nm}$, Fig. 5e and $5 \mathrm{f}$ all exhibit the (110) and (101) lattice fringes, which are found to reflect $d$-spacings of 0.343 and $0.263 \mathrm{~nm}$, respectively. Meanwhile, the selected area electron diffraction (SAED) pattern (Fig. $5 \mathrm{~d}$ ) is well ascribed to the pure phase of $\mathrm{SnO}_{2}$, corresponding to the diffraction peaks of the (110), (101), (211), and (301) planes in the XRD pattern.

In addition, we used V-Sorb 2800P specific surface area analyser to measure the BET surface areas of PPy and composites. As shown on Table 1, the specific surface area of PPy tubes is only $12.65 \mathrm{~m}^{2} / \mathrm{g}$. After loading $\mathrm{SnO}_{2}$ on it, the specific surface areas of $\mathrm{SnO}_{2}-\mathrm{PPy}-1$ and $\mathrm{SnO}_{2}-\mathrm{PPy}-2$ composites increased to $44.04 \mathrm{~m}^{2} / \mathrm{g}$ and $48.32 \mathrm{~m}^{2} / \mathrm{g}$ respectively, due to the $\mathrm{SnO}_{2}$ nanoparticles were loaded on the tubes. For composites, the average pore size which represents the size of pores formed by $\mathrm{SnO}_{2}$ nanoparticles. These pores provide the path to accommodate to the insertion/extraction
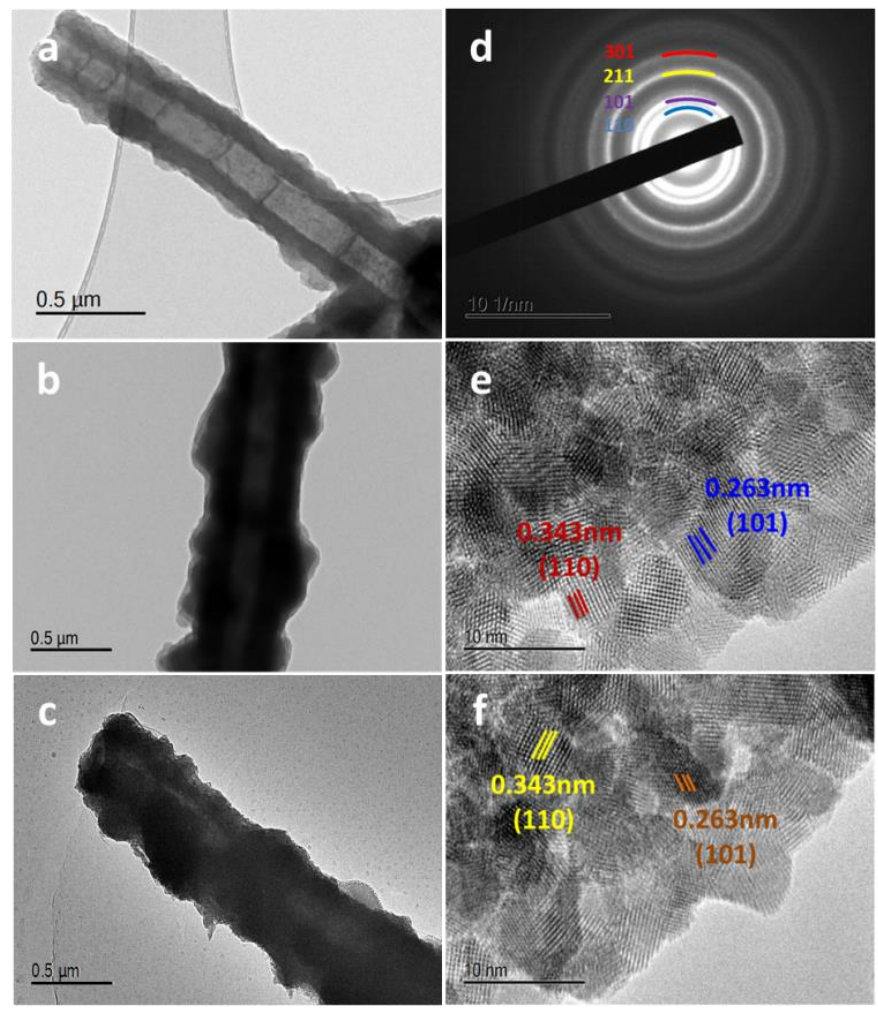

Figure 5 TEM image of PPy (a), low magnification images of $\mathrm{SnO}_{2}-\mathrm{PPy}-1$ (PPy 61.4\%) (b) and $\mathrm{SnO}_{2}-\mathrm{PPy}-2$ (PPy 38.4\%) (c), SAED pattern of $\mathrm{SnO}_{2}-\mathrm{PPy}-2$ (PPy 38.4\%) (d), high magnification images of $\mathrm{SnO}_{2}-\mathrm{PPy}-1$ (PPy 61.4\%) (e) and $\mathrm{SnO}_{2}-$ PPy-2 (PPy 38.4\%) (f).

of sodium ions. As for $\mathrm{SnO}_{2}-\mathrm{PPy}-2$, its' surface area is bigger than $\mathrm{SnO}_{2}-\mathrm{PPy}-1$. This can be inferred to the more content of $\mathrm{SnO}_{2}$ in $\mathrm{SnO}_{2}-\mathrm{PPy}-2$.

Table 1 Key pore characteristics of PPy, $\mathrm{SnO}_{2}-\mathrm{PPy}-1$ and $\mathrm{SnO}_{2}-$ PPy-2

\begin{tabular}{cccc}
\hline Material & $\begin{array}{c}\text { Surface area } \\
\left(\mathrm{m}^{2} \mathrm{~g}^{-1}\right)\end{array}$ & $\begin{array}{c}\text { Pore volume } \\
\left(\mathrm{cm}^{3} \mathrm{~g}^{-1}\right)\end{array}$ & $\begin{array}{c}\text { Average pore } \\
\text { size }(\mathrm{nm})\end{array}$ \\
\hline $\mathrm{PPy}$ & 12.65 & 0.899 & 116.68 \\
$\mathrm{SnO}_{2}$-PPy-1 & 44.04 & 0.332 & 97.01 \\
$\mathrm{SnO}_{2}$-PPy-2 & 48.32 & 0.302 & 95.27 \\
\hline
\end{tabular}

The capacity and coulombic efficiency of the $\mathrm{SnO}_{2}-\mathrm{PPy}-1$ and, $\mathrm{SnO}_{2}-\mathrm{PPy}-2$ composites as a function of cycle number, at a constant current density of $100 \mathrm{~mA} \mathrm{~g}^{-1}$ with a cut-off voltage range from 0.01 to $1.5 \mathrm{~V}$ (vs. $\mathrm{Na} / \mathrm{Na}^{+}$), are presented in Fig. 6a over 150 cycles. To clarify the contribution of the PPy matrix and the bare $\mathrm{SnO}_{2}$ to the electrochemical performance of the $\mathrm{SnO}_{2}$-PPy composites, they were also tested under the same current and voltage conditions. The reversible charge capacity of the $\mathrm{SnO}_{2}-\mathrm{PPy}-2$ composite is about $288 \mathrm{mAh} \mathrm{g}^{-1}$ after 150 cycles, corresponding to $69.1 \%$ of the initial charge capacity. Even though the reversible charge capacity $\mathbf{2 4 6 . 2}$

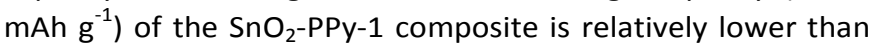
that of the $\mathrm{SnO}_{2}-\mathrm{PPy}-2$ due to the lower content of $\mathrm{SnO}_{2}$, the capacity retention of $74.2 \%$ is higher than for $\mathrm{SnO}_{2}-\mathrm{PPy}-2$. 

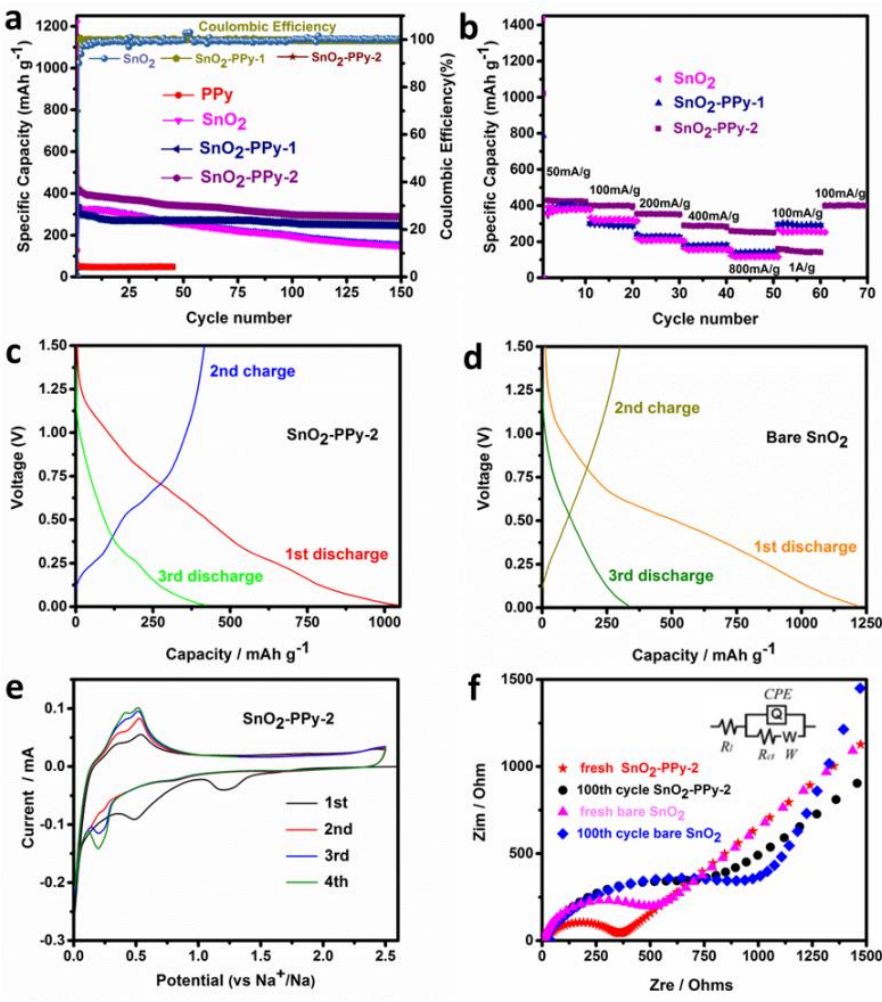

Figure 6 Cycling performances (a) of $\mathrm{SnO}_{2}-\mathrm{PPy}-1$ (PPy 61.4\%), $\mathrm{SnO}_{2}-\mathrm{PPy}-2$ (PPy 38.4\%), bare PPy, and $\mathrm{SnO}_{2}$. Rate capability (b) of $\mathrm{SnO}_{2}$-PPy-1 (PPy 61.4\%), $\mathrm{SnO}_{2}$-PPy-2 (PPy 38.4\%) and bare $\mathrm{SnO}_{2}$. Charge-discharge profiles for the first 3 cycles of $\mathrm{SnO}_{2}-\mathrm{PPy}-2$ (PPy 38.4\%) (c) and bare $\mathrm{SnO}_{2}$ (d). Cyclic voltammetry curves for the first 4 cycles of $\mathrm{SnO}_{2}-\mathrm{PPy}-2$ (PPy $38.4 \%$ ) (e). Nyquist plots and equivalent circuit model (inset) of $\mathrm{SnO}_{2}-\mathrm{PPy}-2$ (PPy 38.4\%) and bare $\mathrm{SnO}_{2}$ (f) for the fresh electrodes and after 100 cycles.

This indicates that a smaller amount of $\mathrm{SnO}_{2}$ nanoparticles can decrease the agglomeration of bare $\mathrm{SnO}_{2}$. The reversible charge capacity is much lower than that of $\mathrm{SnO}_{2}-\mathrm{PPy}-2$, however, and the capacity fading is apparent. The contribution of PPy to the capacity of the $\mathrm{SnO}_{2}$-PPy composites can be neglected.

The coulombic efficiency for both $\mathrm{SnO}_{2}-\mathrm{PPy}-1$ and $\mathrm{SnO}_{2}-\mathrm{PPy}-2$ is near $100 \%$, beginning from the second cycle, indicating that electrons/Na ions are no longer trapped in secondary parasitic reactions that can be introduced by further electrolyte degradation. The stable electrochemical performance of the $\mathrm{SnO}_{2}$-PPy composite and the enhanced capacity benefit from the synergetic effects generated by $\mathrm{SnO}_{2}$ particles on the PPy framework. ${ }^{31}$ This promotes greater conductivity of the $\mathrm{SnO}_{2}$ particles in the case of $\mathrm{SnO}_{2}$-PPy than in the case of nano- $\mathrm{SnO}_{2}$, as suggested by the XPS results (Fig. 2 b).

In addition, the charge/discharge rate capability of the $\mathrm{SnO}_{2}$, $\mathrm{SnO}_{2}-\mathrm{PPy}-1$ and $\mathrm{SnO}_{2}-\mathrm{PPy}-2$ composites were investigated at increasing current rates by progressively increasing the current rate from $50 \mathrm{~mA} \mathrm{~g}^{-1}$ up to $1 \mathrm{~A} \mathrm{~g}^{-1}$ and finally returning it to 100 $\mathrm{mA} \mathrm{g}^{-1}$, in order to test the robustness of the samples. Fig. $6 \mathrm{~b}$ shows the cycling performances of the samples under these different current rate conditions. In the case of $\mathrm{SnO}_{2}-\mathrm{PPy}-2$, the reversible charge capacity of the composite decreases from $428.7\left(50 \mathrm{~mA} \mathrm{~g}^{-1}\right)$, to $400.2\left(0.1 \mathrm{~A} \mathrm{~g}^{-1}\right), 354.2\left(0.2 \mathrm{~A} \mathrm{~g}^{-1}\right)$, $290.1\left(0.4 \mathrm{~A} \mathrm{~g}^{-1}\right), 260.2\left(0.8 \mathrm{~A} \mathrm{~g}^{-1}\right)$, and $160.3 \mathrm{mAh} \mathrm{g}{ }^{-1}\left(1 \mathrm{~A} \mathrm{~g}^{-1}\right)$, respectively, and the composite was found to successfully return to $398.9 \mathrm{mAh} \mathrm{g}^{-1}$ (recovering $99.7 \%$ of its initial capacity) after 60 cycles when the current density was returned to $0.1 \mathrm{~A} \mathrm{~g}^{-1}$. The rate capability of $\mathrm{SnO}_{2}-\mathrm{PPy}-1$ shows lower reversible charge capacity compared to $\mathrm{SnO}_{2}-\mathrm{PPy}-2$. This result is in line with their cycling performances. As for the bare $\mathrm{SnO}_{2}$, we can find this trend that with the increasing of current density, the capacity degraded more severely compared to both composites. Fig. $6 c$ and $6 d$ show the discharge-charge voltage profiles of the initial three cycles for $\mathrm{SnO}_{2}-\mathrm{PPy}-2$ and bare $\mathrm{SnO}_{2}$. The $1^{\text {st }}$ cycle discharge and $2^{\text {nd }}$ cycle charge capacities of $\mathrm{SnO}_{2}-\mathrm{PPy}-2$ composite electrode are 1040.6 and $416.6 \mathrm{mAh} \mathrm{g}^{-1}$, respectively, giving an initial coulombic efficiency of $40 \%$. This is due to the formation of an irreversible solid electrolyte interphase (SEI) layer on the electrode surface and irreversible $\mathrm{Na}$ insertion into the active materials. The initial discharge-charge voltage profiles for bare $\mathrm{SnO}_{2}$ display the $1^{\text {st }}$ cycle discharge capacity of $1217.3 \mathrm{mAh} \mathrm{g}$ ${ }^{1}$ and the $2^{\text {nd }}$ cycle charge capacity of $300.2 \mathrm{mAh} \mathrm{g}^{-1}$, giving a much lower initial coulombic efficiency of $24.7 \%$.

The electrochemical reactions of the $\mathrm{SnO}_{2}-\mathrm{PPy}-2$ nanocomposite were studied by cyclic voltammetry (CV). As shown in Fig. 6e, there is an irreversible transformation of $\mathrm{SnO}_{2}$ into $\mathrm{Sn}$ in the initial discharge process. Weak and irreversible shoulder peaks are seen at 1.4 and $0.6 \mathrm{~V}$ in the first negative scan. These peaks are attributed to some irreversible decomposition of the electrolyte, which forms a (SEI) film on the surface of the $\mathrm{SnO}_{2}-\mathrm{PPy}-2$ composite, and to irreversible reactions between $\mathrm{Na}^{+}$and the active materials. Two reductive peaks are observed at 0.28 and $0.02 \mathrm{~V}$ in the following cycles with different intensities, which are in accordance with the transformation of $\mathrm{Sn}$ into $\mathrm{Na}_{x} \mathrm{Sn}$ alloys. In conformity with the $\mathrm{Na}-\mathrm{Sn}$ binary alloy phase diagrams and previous reports, ${ }^{20,46}$ $\alpha-\mathrm{NaSn}, \mathrm{Na}_{9} \mathrm{Sn}_{4}, \mathrm{Na}_{3} \mathrm{Sn}$, and $\mathrm{Na}_{15} \mathrm{Sn}_{4}$ are the main stable phases. It can be inferred that the reductive peak located at $0.28 \mathrm{~V}$ is related to the formation of a two-phase alloy of $\alpha$ $\mathrm{NaSn}$ and $\mathrm{Na}_{9} \mathrm{Sn}_{4}$. Another reductive peak positioned at around $0.02 \mathrm{~V}$ is considered to be due to the formation of single phase $\mathrm{Na}_{3} \mathrm{Sn}$ and $\mathrm{Na}_{15} \mathrm{Sn}_{4}$. In the reverse positive scan, two oxidative peaks are obviously observed at approximately $0.28 \mathrm{~V}$ and $0.5 \mathrm{~V}$, which indicates that the phase transitions during the de-alloying process had become clear. A hump that appeared at $0.28 \mathrm{~V}$ can be mainly assigned to the de-alloying reactions of $\mathrm{Na}_{3} \mathrm{Sn}$, and $\mathrm{Na}_{15} \mathrm{Sn}_{4}$. The peak at $0.5 \mathrm{~V}$ is due to the $\mathrm{Na}_{9} \mathrm{Sn}_{4}$ de-alloying reactions. ${ }^{47}$

To verify the effects of PPy towards improving the cyclability of $\mathrm{SnO}_{2}-\mathrm{PPy}-2$ electrode, which had better electronic conductivity compared to the bare $\mathrm{SnO}_{2}$ electrode. Electrochemical impedance spectroscopy (EIS) measurement was carried out. The Nyquist plots and the fitting model using an equivalent circuit are depicted in Fig. 6(f), with the equivalent circuit as 


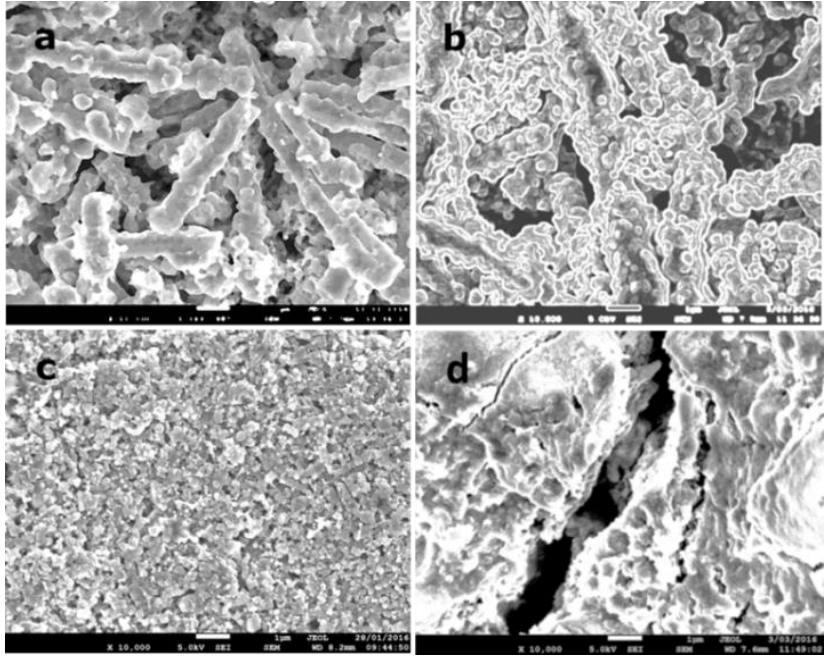

Figure $7 \mathrm{SEM}$ images of the $\mathrm{SnO}_{2}$-PPy-2 (PPy 38.4\%) composite electrodes before the $\mathrm{Na}$-storage test (a) and after 100 cycles (b), and of bare $\mathrm{SnO}_{2}$ before the Na-storage test (c) and after 100 cycles (d).

the inset. Where $R_{i}$ represents the total resistance of the electrolyte, separator, and electrical contacts. The charge transfer resistance $\left(R_{c t}\right)$ can be calculated from the semicircle within the high frequency region, which reflects the impedance related to the sodium ion transport through the film surface and charge transfer between the electrode/electrolyte interfaces. The Warburg impedance (W) is observed from the inclined line in the low frequency region and represents the charge transfer by sodium ion diffusion through the material

or electrolyte. The constant phase element (CPE) in the equivalent circuit is used to simulate an ideal capacitance. It can be observed that the sizes of the depressed semicircles for bare $\mathrm{SnO}_{2}$ in the fresh electrode and after 100 cycles have changed significantly, which indicates that the charge transfer resistance $\left(R_{c t}\right)$ has increased from 494.8 to $898.57 \Omega$. For $\mathrm{SnO}_{2}-\mathrm{PPy}-2$, from the fresh cell to after 100 cycles, Rct of the electrode changed from 358.05 to $715.98 \Omega$, respectively. This implies that the electronic conductivity of the $\mathrm{SnO}_{2}-\mathrm{PPy}-2$ sample was enhanced and benefited from the good electrical conductivity of the PPy in the composite, where it serves as both an active material and a conductor. The morphology of bare $\mathrm{SnO}_{2}$ electrode after cycling shows very obvious cracks (Fig. 7d). No cracks were observed for the $\mathrm{SnO}_{2}-\mathrm{PPy}-2$ composite electrode after cycling, which is attributed to the $\mathrm{SnO}_{2}-\mathrm{PPy}-2$ 3-D structure with void space between the tubes, which could accommodate large volume changes during cycling. Further more, the homogeneous distribution of $\mathrm{SnO}_{2}$ nanoparticles on the PPy tube network is the key factor that provides the balancing force over the whole composite electrode and enhances the long-term electrochemical properties. These results are in good agreement with the EIS conclusions.

\section{Conclusions}

$\mathrm{SnO}_{2}$ nanoparticles were successfully coated on the surfaces of a PPy nanotube network via a simple, convenient, and environmentally friendly method. The obtained 3-D structured $\mathrm{SnO}_{2}$-PPy nanotube network demonstrates good performance as an anode for application in SIBs, especially with regards to the cyclability (over 150 cycles), with a high coulombic efficiency of $99.6 \%$ and good rate capability, recovering up to $99.7 \%$ of the initial charge capacity after several current variation cycles from $50 \mathrm{~mA} \mathrm{~g}^{-1}$ to $1 \mathrm{~A} \mathrm{~g}^{-1}$. These outcomes are attributed to the uniform coating of nanoscale tin dioxide particles on the PPy matrix with unique 3-D structure, which can significantly improve electronic conductivity of composites and acts as a buffer to alleviate the strain resulting from the volume changes in the electrodes during the cycling. At the same time, the diffusion speed of sodium ions is accelerated. On the other hand, a positive synergetic effect between the PPy interfaces and the $\mathrm{SnO}_{2}$ particles is responsible for maximization of the $\mathrm{SnO}_{2}$ conductivity. This is confirmed by the highly uniform distribution of particles. It is further demonstrated by the inferior performance of bare $\mathrm{SnO}_{2}$ particles with similar particle size. Accordingly, our results clearly demonstrate that the coated $\mathrm{SnO}_{2}$ particles on the PPy tubes generate synergetic effects during the cycling, enabling PPy to act as a conductor, which maximizes its utilization during insertion/extraction.

\section{Acknowledgements}

This research work was carried out with financial support from an Australian Research Council (ARC) Discovery Project (DP140100401). The equipment used in the research was funded by an ARC Linkage, Infrastructure, Equipment and Facilities (LIEF) grant (LE0237478), with the facilities located at the UOW Electron Microscopy Centre. The authors would also like to thank Dr. Tania Silver for editing the manuscript.

\section{Notes and references}

1. M. Dahbi, N. Yabuuchi, K. Kubota, K. Tokiwa and S. Komaba, Physical Chemistry Chemical Physics, 2014, 16, 15007-15028.

2. D. Stevens and J. Dahn, Journal of The Electrochemical Society, 2000, 147, 1271-1273.

3. V. Palomares, P. Serras, I. Villaluenga, K. B. Hueso, J. Carretero-González and T. Rojo, Energy \& Environmental Science, 2012, 5, 5884-5901.

4. P. W. Gruber, P. A. Medina, G. A. Keoleian, S. E. Kesler, M. P. Everson and T. J. Wallington, Journal of Industrial Ecology, 2011, 15, 760-775.

5. N. Yabuuchi, K. Kubota, M. Dahbi and S. Komaba, Chemical reviews, 2014, 114, 11636-11682.

6. H. Pan, Y. Hu and L. Chen, Sci, 2013, 6, 2338.

7. B. L. Ellis and L. F. Nazar, Current Opinion in Solid State and Materials Science, 2012, 16, 168-177. 
8.

V. Palomares, M. Casas-Cabanas, E. Castillo-Martínez, M. H. Han and T. Rojo, Energy \& Environmental Science, 2013, 6, 2312-2337.

9. S. Y. Hong, Y. Kim, Y. Park, A. Choi, N.-S. Choi and K. T. Lee, Energy \& Environmental Science, 2013, 6, 2067-2081.

10. A. Ponrouch, E. Marchante, M. Courty, J.-M. Tarascon and M. R. Palacin, Energy \& Environmental Science, 2012, 5, 8572-8583.

11. Y.-M. Li, S.-Y. Xu, X.-Y. Wu, J.-Z. Yu, Y.-S. Wang, Y.-S. Hu, H. Li, L.-Q. Chen and X.-J. Huang, M, J. Mater. Chem. A, 2015, 3, 71-77.

12. Y.-X. Wang, S.-L. Chou, H.-K. Liu and S.-X. Dou, Carbon, 2013, 57, 202-208.

13. H. g. Wang, Z. Wu, F. I. Meng, D. I. Ma, X. I. Huang, L. m. Wang and X. b. Zhang, ChemSusChem, 2013, 6, 56-60.

14. L. Fu, K. Tang, K. Song, P. A. van Aken, Y. Yu and J. Maier, Nanoscale, 2014, 6, 1384-1389.

15. J. M. Fan, J. J. Chen, Q. Zhang, B. B. Chen, J. Zang, M. S. Zheng and Q. F. Dong, ChemSusChem, 2015, 8, 1856-1861.

16. P. Senguttuvan, G. Rousse, V. Seznec, J.-M. Tarascon and M. R. Palacin, Chemistry of Materials, 2011, 23, 41094111.

17. R. Alcántara, M. Jaraba, P. Lavela and J. Tirado, Chemistry of Materials, 2002, 14, 2847-2848.

18. Q. Sun, Q.-Q. Ren, H. Li and Z.-W. Fu, Electrochemistry Communications, 2011, 13, 1462-1464.

19. H. Xiong, M. D. Slater, M. Balasubramanian, C. S. Johnson and T. Rajh, The journal of physical chemistry letters, 2011, 2, 2560-2565.

20. L. Xiao, Y. Cao, J. Xiao, W. Wang, L. Kovarik, Z. Nie and J. Liu, Chemical Communications, 2012, 48, 3321-3323.

21. M. Gu, A. Kushima, Y. Shao, J.-G. Zhang, J. Liu, N. D. Browning, J. Li and C. Wang, Nano letters, 2013, 13, 52035211.

22. D. Su, C. Wang, H. Ahn and G. Wang, Physical Chemistry Chemical Physics, 2013, 15, 12543-12550.

23. X. Meng, Y. Zhong, Y. Sun, M. N. Banis, R. Li and X. Sun, Carbon, 2011, 49, 1133-1144.

24. Y. Wang, D. Su, C. Wang and G. Wang, Electrochemistry Communications, 2013, 29, 8-11.

25. D. Su, H.-J. Ahn and G. Wang, Chemical Communications, 2013, 49, 3131-3133.

26. Y. Zhang, J. Xie, S. Zhang, P. Zhu, G. Cao and X. Zhao, Electrochimica Acta, 2015, 151, 8-15.

$27 . \quad$ R. S. Kalubarme, J.-Y. Lee and C.-J. Park, ACS applied materials \& interfaces, 2015, 7, 17226-17237.

28.

M. Dirican, Y. Lu, Y. Ge, O. Yildiz and X. Zhang, ACS Applied Materials \& Interfaces, 2015, 7, 18387-18396.

29. L. Pei, Q. Jin, Z. Zhu, Q. Zhao, J. Liang and J. Chen, Nano Research, 2015, 8, 184-192.

30. Y.-X. Wang, Y.-G. Lim, M.-S. Park, S. Chou, J. H. Kim, H. Liu, S.-X. Dou and Y.-J. Kim, M, J. Mater. Chem. A, 2014, 2, 529-534.

31. A. Jahel, C. M. Ghimbeu, A. Darwiche, L. Vidal, S. HajjarGarreau, C. Vix-Guterl and L. Monconduit, Journal of Materials Chemistry A, 2015, 3, 11960-11969.

32. L. Yuan, J. Wang, S. Y. Chew, J. Chen, Z. Guo, L. Zhao, K. Konstantinov and H. Liu, Journal of power sources, 2007, 174, 1183-1187.

33. L. Cui, J. Shen, F. Cheng, Z. Tao and J. Chen, Journal of Power Sources, 2011, 196, 2195-2201.
34.

35.

.

36.

.

Du, X.; Yang, T.; Lin, J.; Feng, T.; Zhu, J.; Lu, L.; Xu, Y.; Wang J., Microwave-assisted synthesis of SnO2@ polypyrrole nanotubes and their pyrolyzed composite as anode for lithium-ion batteries. ACS applied materials \& interfaces 2016, 8,15598-15606.

38. X. Yang, Z. Zhu, T. Dai and Y. Lu, Macromolecular rapid communications, 2005, 26, 1736-1740.

39. MA. C., SG. P., PR. G., RN. M., S. S. and VB. P., Soft Nanoscience Letters, 2011, 1,6-10.

40. S. Sakthivel and A. Boopathi, Journal of Chemistry and Chemical Science, 2014, 4, 144-149.

41. J. Ouyang and Y. Li, Polymer, 1997, 38, 3997-3999.

42. G. Cho, B. M. Fung, D. T. Glatzhofer, J.-S. Lee and Y.-G. Shul, Langmuir, 2001, 17, 456-461.

43. M.-S. Park, Y.-M. Kang, J.-H. Kim, G.-X. Wang, S.-X. Dou and H.-K. Liu, Carbon, 2008, 46, 35-40.

44. M. P. Seah and D. Briggs, Practical Surface Analysis: Auger and X-ray Photoelectron Spectroscopy, John Wiley \& Sons, 1990.

45. C. D. Wagner and G. Muilenberg, Handbook of X-ray photoelectron spectroscopy, Perkin-Elmer, 1979.

46. Y. Liu, Y. Xu, Y. Zhu, J. N. Culver, C. A. Lundgren, K. Xu and C. Wang, ACS nano, 2013, 7, 3627-3634.

47. J. Qian, Y. Chen, L. Wu, Y. Cao, X. Ai and H. Yang, Chemical Communications, 2012, 48, 7070-7072. 